Arq. Bras. Med. Vet. Zootec., v.69, n.2, p.305-309, 2017

\title{
Imperfuração congênita do óstio uretral externo associada à persistência de úraco em bezerra Nelore: relato de caso
}

\author{
[Congenital external urethral ostium imperforation associated to urachal \\ persistence in Nelore calf: case report]
}

\author{
J.M. Alonso, C.A. Rodrigues*, A.L.G. Alves, M.J. Watanabe, C. A. Hussni \\ Universidade Estadual Paulista - Unesp - Campus Botucatu, SP
}

\begin{abstract}
RESUMO
A imperfuração uretral associada ou não à persistência do úraco é rara; quando concomitante, o animal mantém o fluxo urinário por via umbilical, entretanto, após o tratamento de correção da persistência do úraco, ocorre o armazenamento de urina, que pode culminar em complicações como bexigoma, hidroureter e ruptura vesical. Uma bezerra Nelore, com 20 dias de idade, foi atendida com persistência de úraco. Prescreveu-se a aplicação local de tintura de iodo a $10 \%$ durante cinco dias, e indicou-se retorno para obliteração cirúrgica caso não houvesse resposta à terapia proposta. Após 30 dias, o animal retornou com distensão abdominal, histórico de diminuição gradual do fluxo urinário, com ausência de micção via vaginal e discreto gotejamento de urina através do umbigo. Após diversas tentativas de cateterismo uretral sem sucesso, diagnosticou-se a imperfuração do óstio uretral externo. O exame ultrassonográfico revelou distensão vesical com aproximadamente sete litros de conteúdo, hidroureter e hidronefrose bilateral. Realizou-se a cistocentese e o esvaziamento vesical guiado por ultrassom e optou-se pela abordagem cirúrgica para criação do óstio uretral e correção do úraco persistente. Por meio de cistotomia, realizou-se a sondagem retrógrada da uretra e a perfuração da membrana que recobria o óstio uretral no vestíbulo vaginal, a fim de criar um novo óstio. A sondagem foi mantida por 10 dias, com o intuito de evitar estenose do óstio e, após 30 dias de pós-operatório, o animal recebeu alta com óstio uretral patente no vestíbulo vaginal.
\end{abstract}

Palavras-chave: bovino, má-formação congênita, onfalopatias, uretra

\begin{abstract}
Urethral imperforation associated or not with urachal patency is rare, when concomitant, the animal maintains urinary flow through umbilical via, but when the treatment is performed storage of urine occurs and can culminate in complications like bexigoma, hydrourether, and vesical rupture. A nelore calf with 20 days of age, was attended with urachal patency, conservative treatment with searing substance (10\% iodine) was prescribed. Return for surgical treatment was recommended if no resolution was achieved. After 30 days, the animal returned with abdominal distension and history of gradual decrease in urinary flow without urination via urethra. Urethral catheterization was attempted, unsuccessfully, and sonographic evaluation revealed vesical distention with approximately seven liters of content, hydrourether and hydronephrosis. cystocentesis and vesical deflation was performed. Surgical approach of the bladder was performed and a new ostium for the urethra in the vaginal vestibule was created by retrograde via. Urachal was removed and urethral catheterization was maintained for 10 days. Following 30 days of pos operative procedure, the animal was discharged.
\end{abstract}

Keywords: bovine, congenital defects, umbilical diseases, urethra

Recebido em 5 de maio de 2016

Aceito em 19 de julho de 2016

*Autor para correspondência (Corresponding author)

E-mail: rodriguesca@fmvz.unesp.br 


\section{INTRODUÇÃO}

Nos ruminantes, a uretra das fêmeas se origina na bexiga e segue em sentido caudodorsal, com sua parede dorsal em aposição à parede ventral da vagina, abrindo-se ventralmente no assoalho da vagina, sob forma de fenda na junção vestibular da vagina com o divertículo suburetral. Essa abertura é denominada de óstio uretral externo (Dyce et al., 2010).

A imperfuração do óstio uretral externo manifesta-se por falha na passagem da urina e distensão da porção patente da uretra, da bexiga e dos ureteres (Radostitis et al., 2000). A associação da imperfuração uretral e a persistência do úraco é rara, tendo sido descrita por Hunt e Allen (1989) e por Hylton e Trent (1987), ambas em fêmeas Charolesas.

Ressalta-se, por meio deste relato, a importância da avaliação da patência do óstio uretral externo ao exame físico dos animais portadores de persistência de úraco, pois o diagnóstico concomitante dessas enfermidades e o tratamento prévio da imperfuração uretral previnem a ocorrência de complicações, como ruptura vesical, perda da função renal e óbito do paciente.

\section{RELATO DO CASO}

Foi atendida uma bezerra Nelore de 20 dias de idade, com histórico de micção exclusiva por via umbilical desde o nascimento. Ao exame físico, notou-se fluxo urinário umbilical e espessamento na região, além de discreta secreção purulenta local. Foi prescrito o uso de tintura de iodo a
$10 \%$, injetando-se $2 \mathrm{~mL}$ do produto através do orifício uracal, durante cinco dias consecutivos, e a administração sistêmica de $20 \mathrm{mg} / \mathrm{kg}$ de florfenicol (Florkem ${ }^{\circledR}$, Florfenicol, Ceva, Brasil) por via subcutânea, a cada $48 \mathrm{~h}$, durante 10 dias. Recomendou-se retorno do animal após o tratamento caso não houvesse resolução do problema. Após 30 dias, o animal retornou apresentando marcante distensão abdominal e escasso gotejamento de urina pelo umbigo. O proprietário informou que, desde o término do tratamento, notara apenas gotejamento pelo umbigo, que reduzia a cada dia, e que nunca havia observado o animal urinar pela vulva. $\begin{array}{lccc}\text { Ao exame } & \text { físico, o } & \text { animal } & \text { apresentava } \\ \text { frequências } & \text { cardíaca } & \mathrm{e} & \text { respiratória, }\end{array}$ respectivamente, de $105 \mathrm{bpm}$ e $80 \mathrm{mpm}$, com leve dispneia, mucosas róseas e turgor de pele normal. Foram realizadas algumas tentativas de sondagem uretral sem sucesso. A ultrassonografia abdominal caracterizou dilatação da bexiga urinária, que ocupava grande parte da cavidade abdominal, com volume aproximado de 7,22 litros (Figura 1). Foi evidenciado também espessamento da parede da bexiga e presença de estrutura tubular com conteúdo anecogênico, em direção ao ônfalo, sugestivo de úraco persistente. Imediatamente procedeu-se à cistocentese guiada pelo ultrassom e à drenagem vesical, retirando-se aproximadamente oito litros de urina (Figura 2). A ultrassonografia identificou ainda a presença de estrutura tubular, adjacente à pelve renal, com conteúdo anecogênico, sem fluxo ao Doppler colorido, medindo $1,48 \mathrm{~cm}$ de diâmetro do lado esquerdo e $1,92 \mathrm{~cm}$ do lado direito, compatível com hidroureter (Figura 1).
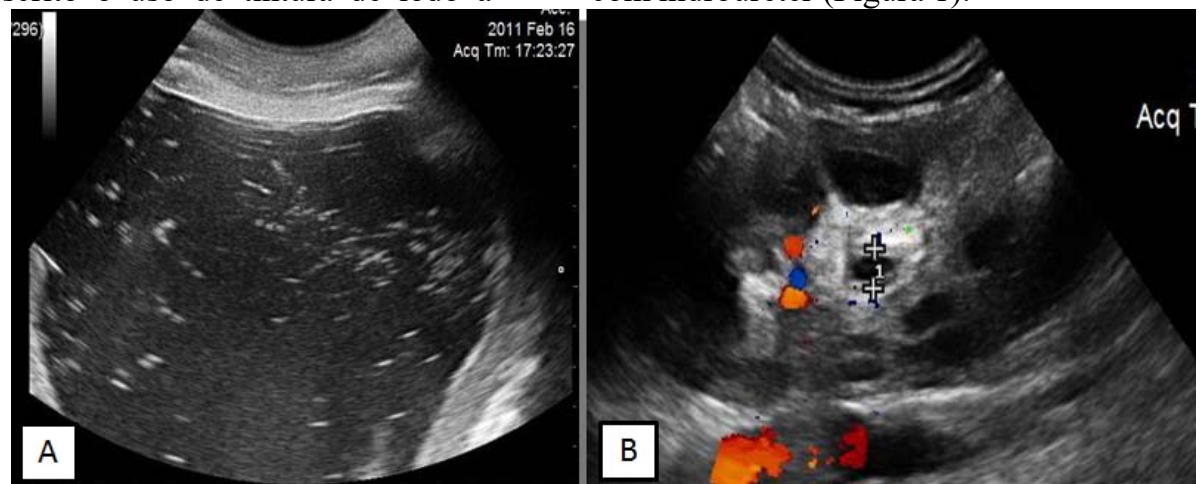

Figura 1. Imagens ultrassonográficas da bezerra Nelore com imperfuração do óstio uretral externo. Abexiga demonstrando distensão por conteúdo anecogênico com pontos ecogênicos em suspensão (sedimentos). B- imagem ultrassonográfica do rim esquerdo demonstrando dilatação de pelve $(0,8 \mathrm{~cm}) \mathrm{e}$ vascularização ao Color Doppler. 


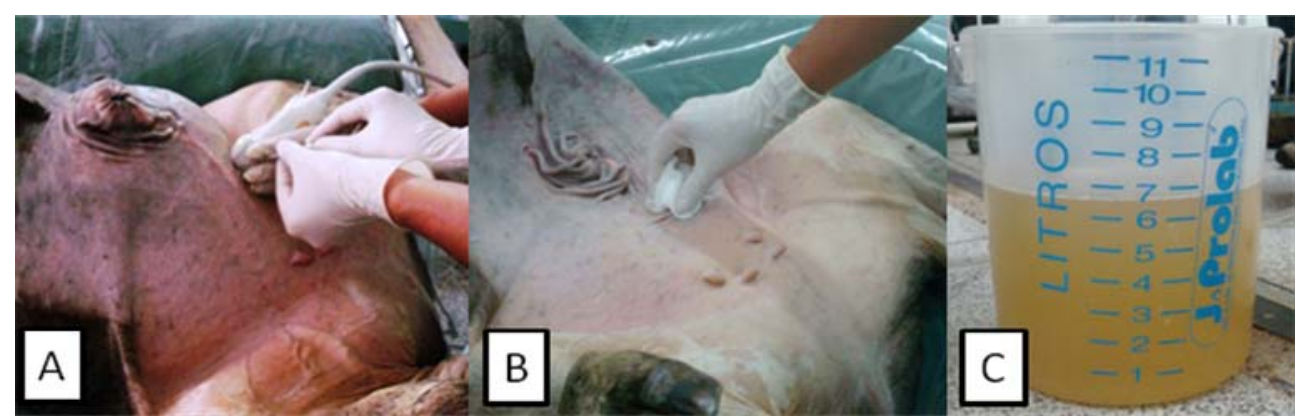

Figura 2. Esvaziamento vesical de bezerra Nelore previamente ao procedimento cirúrgico para correção de imperfuração do óstio uretral externo. A- cistocentese guiada por ultrassom. É possível notar o abaulamento do abdômen devido à repleção vesical. B- aspecto do abdômen após o esvaziamento da bexiga. C- volume de urina retirada.

O bovino foi submetido à laparotomia exploratória retroumbilical. Nesta, procedeu-se à identificação da vesícula urinária, à cistotomia e à sondagem uretral retrógrada, confirmando-se a imperfuração uretral, mediante o abaulamento do assoalho da vagina decorrente da pressão da sonda na região correspondente ao óstio uretral externo. Posteriormente, pela via vaginal e com auxílio de um guia metálico, realizou se a abertura uretral de aproximadamente $0,6 \mathrm{~cm}$. Através do óstio uretral externo, em sentido anterógrado, posicionou-se um cateter de Foley de silicone de 30 Fr (Coloplast, Brasil) e insuflou-se o cuff na região da bexiga. Foi realizada cistorrafia em padrão Schiemiden, com fio de poliglactina $910(\mathrm{Vycril} \AA$, Poliglactina 910, Ethicon, Brasil) 2-0, seguida de Cushing com mesmo material. O ônfalo foi removido, e a síntese da cavidade abdominal realizada em padrão Sultan, com fio de poliglactina 910, número 2. A síntese da pele foi realizada com fio de náilon 1 (Nylon, fio monofilamentar de náilon, Brasuture, Brasil) em padrão simples separado. Procedeu-se à terapia antimicrobiana profilática, no momento da medicação préanestésica, com $4 \mathrm{mg} / \mathrm{kg}$ de ceftiofur (Topcef®, Ceftiofur, Pearsson/Euroframa, Brasil), pela via intravenosa. A terapia se estendeu durante sete dias, sendo acrescido meloxicam (Maxicam ${ }^{\circledR}$, Meloxicam, Ouro Fino, Brasil) na dose de $0,6 \mathrm{mg} / \mathrm{kg}$, por via intramuscular, durante 10 dias consecutivos.

No pré-operatório, obtiveram-se valores de ureia (U) e creatinina (C) de $231 \mathrm{~g} / \mathrm{dL}$ e $7,0 \mathrm{~g} / \mathrm{dL}$, respectivamente. Ao sétimo, $13^{\circ}$ e $21^{\circ}$ dias de pós-operatório, os valores foram, respectivamente, de U: 280, C:12; U: 269, C: 5,3; U: 220, C: 4,5g/dL.
No sétimo dia pós-cirúrgico, o animal apresentou aumento na frequência de miç̧ão eurina com odor fétido. A urinálise revelou diminuição significativa da densidade, intensa colonização bacteriana, aumento do número de leucócitos por campo, além da presença de glicose e sangue oculto na urina. Realizou-se terapia com norfloxacina (Norflomax ${ }^{\circledR}$, Norfloxacina, Ouro Fino, Brasil) na dose de $7 \mathrm{mg} / \mathrm{kg}$, a cada 24 horas, durante sete dias, por via intramuscular.

O cateter de Foley foi mantido por 10 dias de pós-operatório e, após esse período, removido. Após a retirada do cateter, o animal apresentou gotejamento constante de urina pela vulva durante três dias e, a partir de então, manteve micção normal. $\mathrm{O}$ animal recebeu alta com aproximadamente 30 dias de pós-operatório.

\section{DISCUSSÃO}

A imperfuração do óstio uretral externo é infrequente e, quando associada à persistência do úraco, é ainda mais rara. Não existem descrições de complicações decorrentes da correção da persistência do úraco associada à imperfuração uretral. Hunt e Allen, em 1989, referiram-se a um caso de persistência de úraco associada à imperfuração uretral em uma bezerra, entretanto o diagnóstico da imperfuração foi realizado concomitantemente à terapia de correção da persistência do úraco.

As anormalidades uretrais congênitas incluem agenesia, imperfuração, duplicação, divertículo, fístula uretrofecal e estenose (Wolfe, 1986; Weaver et al., 1992; Javdani et al., 2009). Baseando-se nos achados clínicos, inicialmente suspeitou-se de agenesia ou imperfuração uretral. 


\section{Alonso et al.}

Ambas são anomalias congênitas raras. A agenesia uretral foi descrita em um bezerro de quatro dias de idade no segmento distal da uretra peniana (Javdani et al., 2009) e em uma bezerra Holandesa de 10 dias (Nikahval e Ahrari Khafi, 2013) e a imperfuração do óstio uretral externo foi descrita em duas bezerras Charolesas (Hunt e Allen, 1989; Hylton e Trent, 1987).

Apesar de as anomalias congênitas do trato gênito-urinário, como a agenesia e a imperfuração uretral, serem mais frequentes nos machos e geralmente associadas com a agenesia peniana (Fahmy, 2015), neste relato a anomalia é descrita em uma fêmea, assim como descrito por Hunt e Allen (1989), Hylton e Trent (1987) e Nikahval e Ahrari Khafi (2013). O relato duplo na literatura de ocorrência da imperfuração uretral em fêmeas Charolesas abriu precedentes para a discussão do caráter genético e hereditário para tal enfermidade (Hunt e Allen, 1989). Entretanto, não existem relatos da ocorrência de tal afecção em animais da raça Nelore como observado no presente caso.

O tratamento tradicional do úraco persistente é a cauterização química com fenol, iodo a $10 \%$ ou nitrato de prata, sendo indicada a exploração e ressecção cirúrgica do úraco e de vasos umbilicais após cinco a sete dias, nos casos não responsivos ao tratamento clínico (Marques et al., 2010; Rodrigues et al., 2010). A utilização da cauterização química com iodo a $10 \%$ foi parcialmente efetiva como estimulo local para a correção da persistência do úraco, visto que, após 30 dias, ainda havia gotejamento de urina através do umbigo. Entretanto, o não fechamento pode ter sido decorrente da má-formação uretral, visto o úraco ser a única via patente para a eliminação da urina. A falha da terapia para o fechamento do úraco foi positiva, pois preveniu a ruptura vesical.

O exame ultrassonográfico é uma ferramenta diagnóstica útil para avaliar alterações do trato urinário, pode ser utilizado para diagnosticar pielonefrite, urolitíase, hidronefrose, cistos renais, tumores, amiloidose, cistite, atonia vesical, ruptura vesical, ocasionalmente glomerulonefrite e nefrite embólica (Floeck, 2009). No presente caso, foi possível confirmar a suspeita clínica de distensão vesical não acompanhada de ruptura e constatar que o acúmulo de urina estava desencadeando hidroureter e hidronefrose bilateral.

A técnica cirúrgica empregada para a correção da imperfuração uretral foi semelhante à descrita por Hunt e Allen (1989), entretanto foi utilizado um guia metálico para a identificação de membrana de oclusão do meato urinário externo, visto que a sonda uretral de polietileno ou o cateter de Foley não ofereciam suporte e resistência para permitir a incisão e a abertura do óstio uretral externo.

Com o objetivo de evitar a estenose do óstio criado cirurgicamente, optou-se pela manutenção do cateter de Folley por 10 dias. O período proposto foi eficaz na prevenção de estenose, entretanto permitiu a contaminação ascendente do trato gênito-urinário. Hunt e Allen (1989) removeram o cateter de Foley após 24 horas do procedimento cirúrgico, a fim de evitar contaminações ascendentes, e não descrevem a ocorrência de estenose como complicação da técnica cirúrgica.

Após retirada do cateter e aplicação sistêmica da norfloxacina, ocorreu normalização da urinálise, melhora clínica e no odor da urina. Foi observado que, nos três primeiros dias após a retirada do cateter, houve gotejamento constante de urina por via vaginal e, após esse período, o animal recuperou o tônus vesical e manteve micção normal. Sugere-se que a manutenção da sondagem por 10 dias resultou em incontinência transitória, como descrito frequentemente em humanos submetidos a cirurgias prostáticas e mantidos sondados por longos períodos (Van Kampen et al., 2000).

A avaliação da função renal previamente à cirurgia caracterizou azotemia com origem pósrenal, o acúmulo e a estase de urina desencadearam hidronefrose e hidroureter, o que possivelmente resultou em instalação de lesão renal, que foi constatada por meio da avaliação seriada da função renal pós-operatória. Ao longo da terapia pós-cirúrgica, o animal foi mantido na fluidoterapia. Possivelmente, a recuperação da função renal foi lenta devido à presença de lesão renal decorrente da hidronefrose.

A associação do quadro clínico do animal e os exames complementares proporcionaram a avaliação do grau de comprometimento dos 
órgãos urinários relacionados, bem como a avaliação da recuperação deles e a eficácia do tratamento empregado.

\section{CONCLUSÃO}

Indica-se, com base na experiência obtida neste atendimento e na literatura existente acerca dessa afecção, que, ao se realizar o exame clínico de animais portadores de persistência de úraco, seja acrescentado a este exame a avaliação da patência do óstio uretral externo. No presente caso, a identificação da imperfuração uretral foi tardia e culminou na ocorrência das complicações descritas. A realização da inspeção uretral no atendimento inicial é de fácil realização, não demanda exames complementares e impede o comprometimento do animal com a ocorrência de complicações e até mesmo o óbito.

Apesar da escassa descrição e da baixa ocorrência, a imperfuração do óstio uretral externo é uma afecção congênita que pode levar a complicações graves se negligenciada. Este estudo ressalta a importância de se realizar a avaliação da patência do óstio uretral externo nos casos de persistência de úraco.

\section{REFERÊNCIAS}

DYCE, K.M.; SACK, W.O.; WENSING, C.J.G. Tratado de anatomia veterinária. 4.ed. Rio de Janeiro: Elsevier, 2010. 700p.

FAHMY, M. Rare congenital genitourinary anomalies: an illustrated reference guide. Berlin: Springer-Verlag, 2015. p.122-123.

FLOECK, M. Ultrasonography of bovine urinary tract disorders. Vet. Clin. N. Am. Food Anim. Pract., v.25, p.651-67, 2009.

HUNT, R.J.; ALLEN, D.J.R. Treatment of patent urachus associated with a congenital imperforate urethra in a calf, Cornell Vet. v.79, p.157-60, 1989.
HYLTON, W.; TRENT, A. Congenital urethral obstruction, uroperitoneum, and omphalitis in a calf. J. Am. Vet. Med. Assoc. v.190, p.433-434, 1987.

JAVDANI GANDOMANI, M.; DEHGHANI NAZHVANI, S.; RAAYAT JAHROMI, A.R. Congenital penile urethral aplasia in a 4-day-old bull calf. Iran. J. Vet. Res., v.10, p.87, 2009.

MARQUES, L.C.; MARQUES, J.A.; MARQUES, I.C.S.; TEIXEIRA, M.C.A. Dilatação cística do úraco e uroperitônio em touros: relato de cinco casos. Arq. Bras. Med. Vet. Zootec. v.62, p.1320-1324, 2010.

NIKAHVAL, B.; AHRARI KHAFI, M.S. Congenital persistent urachus, urethral obstruction and uroperitoneum in a calf. Iran. J. Vet. Res. v.14, p.158-160, 2013.

RADOSTITIS, O.M.; GAY, C.C.; BLOOD, D.C.; HINCHCLIFF, K.W. Clínica veterinária: um tratado das doenças dos bovinos, ovinos, suínos, caprinos e equinos. 9.ed. Rio de Janeiro: Guanabara Koogan, 2000. 446p.

RODRIGUES, C.A.; SANTOS, P.S.; SILVIA HELENA, V. et al. Correlação entre os métodos de concepção, ocorrência e formas de tratamento das onfalopatias em bovinos: estudo retrospectivo. Pesq. Vet. Bras. v.30, p.618-622, 2010.

VAN KAMPEN, M.; WEERDT, W.; VAN POPPEL, H. et al. Effect of pelvic-floor reeducation on duration and degree of incontinence after radical prostatectomy: a randomised controlled trial. Lancet, v.355, p.98-102, 2000.

WEAVER, A.D.; JOHNSON, G.C.; HILL, J. Congenital megalourethra in a male Charolais calf. Can. Vet. J. v.33, p.270-272, 1992.

WOLFE, D.F. Surgical procedure of the reproductive system of the bull. In: MORROW D.A. Current therapy in theriogenology. 2.ed. Philadelphia: W.B. Saunders, 1986. p.353-397. 